\title{
New Technical Regulation in the Eurasian Economic Union: Restrictions on Certain Substances in Electrotechnical and Radio- Electronic Products
}

\author{
Michael Öttinger and Yulia Arkadyevna Leonova*
}

The use of substances with hazardous properties has been regulated by legal requirements within the EU for decades. Increasing public awareness and a stronger enforcement practice by the authorities are moving the area of substance-related specifications for products further into focus. Especially for manufacturers of electrical and electronic equipment (EEE) it is essential to know their role in the supply chain of EEE and to comply with their respective obligations, in particular with applicable substance restrictions. This article provides for an overview about the European Directive 2011/65/EU on the restriction of the use of certain hazardous substances in electrical and electronic equipment (RoHS EU) and compares this well-established regime with the requirements laid down in the new Technical Regulation of the Eurasian Economic Union of the restriction of the use of hazardous substances in electrotechnical and radio-electronic products (TR EAEU 037/2016).

\section{RoHS EU and TR EAEU 037/2016 in Brief}

The current RoHS-Directive ${ }^{1}$ was published on 1 July 2011 and entered into force in the European Union on 21 July 2011. According to Article 288(3) of the Treaty on the Functioning of the European Union (TFEU) 'a directive shall be binding, as to the result to be achieved, upon each Member State to which it is addressed, but shall leave to the national authorities the choice of form and methods.' In other words, each European Member State had to transpose the RoHS-Directive into national law without being restricted in the form and methods of achieving the aims of the Directive. As a consequence, there are (slight) differences between the national requirements regarding RoHScompliance within the EU, however, the requirements of RoHS EU are in general applicable within the whole European Union (including UK so far). In Germany, for example, RoHS EU is transposed into national law by the German Ordinance on hazardous Substances in Electrical and Electronic Equipment (ElektroStoffV). ${ }^{2}$

For the purposes of life and health protection, environment preservation, prevention of customer deception and fostering of energy efficiency and economical use of resources, the Eurasian Economic Union (EAEU) adopted the Technical Regulation of the Eurasian Economic Union TR EAEU 037/2016 on restriction of use of certain hazardous substances in electrotechnical and radio-electronic products (in Russian - Технический регламент Евразийского экономического союза 'Об ограничении применения опасных веществ в изделиях электротехники и радиоэлектроники (ТР EАЭС 037/2016)). ${ }^{3}$ Initially, it was supposed to take effect on 1 March 2018. But in its Resolution No. 24 of 28 February 2017, the Commission of the Eurasian Economic Commission postponed its implementation until 1 March 2020. The time period from 1 March 2018 until 1 March 2020 was a 'transition period' to give com-

DOI: $10.21552 / \mathrm{icrl} / 2020 / 1 / 5$

* Michael Öttinger is attorney-at-law and associate at the Produktkanzlei - Ahlhaus Niermeier Schucht Rechtsanwaltsgesellschaft mbH. For correspondence: oettinger@produktkanzlei.com; Yulia Arkadyevna Leonova is legal counsel at Sberbank of Russia.

1 Directive 2011/65/eu of the European Parliament and of the Council of 8 June 2011 on the restriction of the use of certain hazardous substances in electrical and electronic equipment (recast).

2 Available at: <https://www.gesetze-im-internet.de/elektrostoffv/ ElektroStoffV.pdf>

3 Resolution of the Council of the Eurasian Economic Commission No. 113 of 18 October 2016, Available at <http://www.consultant ru/document/cons_doc_LAW_209378/ f8e9ca712ca8fda6e3a51938efa605do0fbeb6ea/> 
panies the opportunity to get documents confirming the compatibility of the products with the mandatory rules of TR EAEU 037/2016. Although the Technical Regulation was adopted by a Resolution of the EAEU, no further legislation will be necessary in the Member States of the EAEU (the Republic of Belarus, the Republic of Kazakhstan, the Russian Federation, the Kyrgyz Republic and the Republic of Armenia), because technical regulations of the EAEU have direct effect on the whole territory of the EAEU. ${ }^{4}$

With respect to the application of the TR EAEU 037/2016 on 1 March 2020, it should be noted that until this date, electrotechnical and radio-electronic products could be manufactured and released into circulation without a conformity check and without any documents confirming the fulfillment of TR EAEU 037/2016 requirements. In the context of the Technical Regulation, 'release into circulation' means delivery or import of products (dispatch from the warehouse of the manufacturer and delivery without previous storage included) with the aim of further distribution in return for payment or free of charge within the borders of the EAEU as a part of commercial activities. ${ }^{5}$ Once released into circulation, electrotechnical and radio-electronic products (before March 1, 2020) are allowed to circulate until the expiry of their useful life as defined by the law of the respective EAEU Member State.

\section{Scope of Application and Roles in the Supply Chain}

Besides the general scope of application of RoHS EU and TR EAEU 037/2016 (cf. under 1.), it is essential to know the role of a market actor in the supply chain (cf. under 2.) in order to determine its respective obligations.

\section{Scope of Application}

Although the core definition of 'electronic and electrical equipment' according to Article 3(1) RoHS EU

4 Clause 52, Part 2 of the Treaty of the Eurasian Economic Union (signed in Astana on 29 May 2014), Available at <http://www .consultant.ru/document/cons_doc_LAW_163855/>

5 No. 26, Section 2 of Annex 9 to the Treaty of the Eurasian Economic Union. and 'electrotechnical and radio-electronic products' according to Section 4, Paragraph II in conjunction with Section 3.a), Paragraph I TR EAEU 037/2016 is similar, there are partially significant differences regarding products, which are not within the scope of the respective piece of legislation.

According to Article 3(1) RoHS EU, the term 'electronic and electrical equipment' is defined as 'equipment which is dependent on electric currents or electromagnetic fields in order to work properly and equipment for the generation, transfer and measurement of such currents and fields and designed for use with a voltage rating not exceeding 1 ooo volts for alternating current and 1500 volts for direct current.' The term 'dependent' in this context means, according to Article 3(2) RoHS EU, that the EEE needs 'electric currents or electromagnetic fields to fulfil at least one intended function.'

The TR EAEU 037/2016 defines 'electrotechnical and radio-electronic products' (in Russian -изделия электротехники и радиоэлектроники) as products, the intended use of which 'depends on the presence, application, generation, transformation, transmission and distribution of electric currents and/or electromagnetic fields and which are used either on their own or constitute a part of a machine, mechanism, apparatus, instrument or other equipment' (No. 3, Section 4, Paragraph II TR EAEU 037/2016).

It should be pointed out that TR EAEU 037/2016 does not apply to 'electrotechnical and radio-electronic products' which are 'designed to be used with voltages of no more than 1000 volts for alternating currents and 1500 volts in the case of direct currents, unless otherwise stipulated by Annex 1 TR EAEU 037/2016.' Another aspect worth noting is that TR EAEU 037/2016 does not apply to electrotechnical and radio-electronic components which are used as constituent parts of electrotechnical and radio-electronic equipment not mentioned in Annex 1 TR EAEU 037/2016.

Additionally, TR EAEU 037/2016 is, inter alia, not applicable on electrical toys (Section 3.c), Paragraph I. TR EAEU 037/2016), measurements tools/instruments (Section 3.i), Paragraph I. TR EAEU 037/2016) and medical products (Section 3.j), Paragraph I. TR EAEU 037/2016), whereas EEE of these categories are generally covered by RoHS EU.

In general, starting from 22 July 2019, RoHS EU is applicable on all EEE without limitations, apart from exemptions explicitly laid down in Article 2(4) 
RoHS EU. These exemptions include, inter alia, 'large-scale stationary industrial tools' and 'largescale fixed installations', which however does not per se exclude machinery within the meaning of Directive 2006/42/EC from the scope of application of RoHS EU. Although 'large-scale stationary industrial tools' (Article 2(4)(d) in conjunction with Article 3(3) RoHS EU) and 'large-scale fixed installations' (Article 2(4)(e) in conjunction with Article 3(4) RoHS EU are not explicitly excluded from TR EAEU 037/2016, these types of EEE are not covered by Annex I TR EAEU 037/2016 and thus it is not applicable on these types of products according to its Section 2, Paragraph I.

\section{Roles in the Supply Chain}

With regard to the roles under RoHS EU, it has to be differentiated between the 'manufacturer', the 'authorised representative', the 'distributor' and the 'importer'.

A 'manufacturer' is defined in Article 3(6) RoHS $\mathrm{EU}$ as 'any natural or legal person who manufactures an EEE or who has an EEE designed or manufactured and markets it under his name or trademark.'

According to Article 3(7) RoHS EU the term 'authorised representative' is defined as 'any natural or legal person established within the Union who has received a written mandate from a manufacturer to act on his behalf in relation to specified tasks.' Unlike under Directive 2012/19/EU on waste electronical and electronic equipment (WEEE EU) $)^{6}$, there is no obligation for manufacturers under RoHS EU to appoint an EU-based authorized representative, however it is possible. It has to be noted that the same entity appointed as authorised representative by a non-EU-based market actor according to Article 17 WEEE EU may act upon such an appointment as authorised representative under RoHS EU as well.

The term 'distributor' is defined in Article 3(8) RoHS EU as 'any natural or legal person in the supply chain, other than the manufacturer or the importer, who makes an EEE available on the market.'

Finally, an 'importer' is 'any natural or legal person established within the Union, who places an EEE from a third country on the Union market' (Article 3(9) RoHS EU).

Under RoHS EU it is crucial to clearly delimitate these roles, since different obligations are connect- ed with each role. Against the background of numerous interlinkages of a single market actor within numerous supply chains, the role of a market actor cannot be determined once for a company as such, but has to be assessed for each interaction in the supply chain of the company under assessment. In most cases this assessment leads to the conclusion that a specific company has different roles with respect to different products, eg on the one hand importer for a product for which the company is responsible at the point in time when the product enters the EU and on the other hand distributor for a product which is manufactured by another company in the same country in which the company under assessment is located.

In the Russian Federation and the EAEU, exactly as in the EU, there is a difference between a manufacturer, an authorised representative and an importer. Although distributors are independent market actors, the lawmaker has not provided for a definition in TR EAEU 037/2016.

A 'manufacturer' in the terms of EAEU legislation means a 'legal or natural persons registered as sole entrepreneurs, including foreign manufacturers that produce (and sell) the goods in their own name and are responsible for the conformity of the produce with technical regulations of the EAEU."

An 'authorised representative of the manufactur$e^{\prime}$ ' is a 'legal or natural persons that is registered as sole entrepreneurs in a EAEU Member State according to the procedure established by its law, and who, as convened in an agreement, acts on behalf of the manufacturer during the verification of conformity and release of the products into circulation in the Union and who will be liable for any violations of TR EAEU 037/2016. ${ }^{8}$

According to No. 4, Section 4, Paragraph II TR EAEU 037/2016 an 'importer' is a 'resident of the EAEU Member State who entered into a foreign trade agreement with a non-resident concerning the handover of electrotechnical and radio-electronic products, sells the goods and will be liable for any violations of TR EAEU 037/2016.'

6 Available at <https://eur-lex.europa.eu/legal-content/EN/TXT/PDF/ ?uri=CELEX:02012L0019-20180704\&from $=E N>$

7 No. 9, Section 2 of Annex 9 to the Treaty on the Eurasian Economic Union.

8 No. 26, Section 2 of Annex 9 to the Treaty on the Eurasian Economic Union. 
The main tasks manufacturers, authorised representatives and importers under TR EAEU 037/2016 are charged with are (1) to obtain the documents confirming the conformity of the products and (2) to ensure the availability of the documents that confirm the compatibility of the products with the requirements of TR EAEU 037/2016. It has to be noted that this confirmation can only be made by Russian companies, companies located in the EAEU, or foreign companies, provided that they are registered in an EAEU Member State.

\section{Substance Restriction}

First of all, it can be stated that the reference object for the determination of the applicable concentration thresholds is not the EEE as such, but each homogeneous material of the EEE. According to Article 3(20) RoHS EU and similar according to Section 4, Paragraph II. TR EAEU 037/2016, a 'homogeneous material' is 'one material of uniform composition throughout or a material, consisting of a combination of materials, that cannot be disjointed or separated into different materials by mechanical actions such as unscrewing, cutting, crushing, grinding and abrasive processes.' This means for example that a plastic casing of an EEE is considered a homogeneous material and the coating of the plastic casing is another homogeneous material. ${ }^{9}$

\section{RoHS EU}

The substance restrictions applicable for EEE within the European Union are laid down in Article 4 in conjunction with Annex II RoHS EU. The following sub-

9 Please note that under the European Regulation (EC) No $1907 / 2006$ (REACH), the coated plastic casing would qualify as one 'article' in the sense of Article 3(3) REACH and thus the reference object for the threshold for information obligations regarding substances of very high concern (SVHC) established in Article $33 \mathrm{REACH}$ is the coated plastic casing as such. There is no need under REACH for a further breakdown on the level of the homogeneous materials, unlike under RoHS EU.

$10 \mathrm{Cf}<\mathrm{https}$ ://rohs.exemptions.oeko.info/fileadmin/user_upload/ RoHS_Pack_15/4th_Consultation/TBBPA_RoHS_Dossier_V2_final _20191204.pdf>

$11 \mathrm{Cf}<$ https://rohs.exemptions.oeko.info/fileadmin/user_upload/ RoHS_Pack_15/4th_Consultation/MCCPS_RoHS_Dossier_revised _20191205_final.pdf $>$

12 Cf. <https://rohs.exemptions.oeko.info/index.php?id=347> stances are restricted with the corresponding threshold per homogeneous material in brackets:

- Lead $(0,1 \%)$,

- Mercury $(0,1 \%)$,

- Cadmium (0,01\%),

- Hexavalent chromium (0,1\%),

- Polybrominated biphenyls (PBB) (o,1 \%),

- Polybrominated diphenyl ethers (PBDE) (0,1 \%)

- Bis(2-ethylhexyl) phthalate (DEHP) (0,1\%),

- Butyl benzyl phthalate (BBP) (0,1 \%),

- Dibutyl phthalate (DBP) (0,1 \%) and

- Diisobutyl phthalate (DIBP) (o,1\%)

Currently two substances have been proposed for inclusion in the list of substance restrictions under RoHS EU according to Article 6 RoHS EU, both with a concentration threshold of $0,1 \%$. These are the following two substances:

- Tetrabromobisphenol-A (TBBP-A) ${ }^{10}$ and

- medium-chain chlorinated paraffins (MCCPs) $)^{11}$

Due to the lack of legal provisions on the timing, it is currently still unclear when the European Commission will take a final decision on the inclusion of these substances in Annex II RoHS EU. However, it can be assumed that a possible restriction will not apply immediately, but that a transitional period of several years will be granted during which the companies concerned can adjust to the new restrictions.

In addition to the substances mentioned here, there is a longer list of 43 substances $^{12}$, which will be evaluated in several stages with regard to their inclusion in Annex II RoHS EU.

Substance and use specific exemptions from these substance restrictions are contained in Annex III and Annex IV RoHS EU, which are applicable according to Article 4(6) RoHS EU. Exceptions are either provided for completely without concentration thresholds (for example in entry No. 4 f Annex III RoHS EU for 'mercury in other discharge lamps for special purposes not specifically mentioned in this Annex') or again with separate concentration thresholds (for example in entry No. 4a Annex III RoHS EU for 'mercury in other low pressure discharge lamps (per lamp); (...)15 mg may be used per lamp after 31 December 2011').

All exemptions laid down in Annexes III and IV RoHS EU are only valid for maximum five or seven years respectively, depending on the involved product type, but may be renewed by the European Com- 
mission for another maximum five or seven years upon application by a market actor. In case no application for renewal is submitted at least 18 month before the expiry date the exemption in question, it expires at the point in time mentioned in the entry for the exemption in question in Annex III or IV RoHS EU with the consequence that the substance restrictions are applicable starting from the expiry date. In case an application for renewal is rejected or an exemption is revoked by the European Commission, the exemption will remain valid for 12 to 18 months, as determined in the underlying decision, after the date of the decision before it expires. ${ }^{13}$

\section{TR EAEU 037/2016}

According to Paragraph IV of the TR EAEU 037/2016, electrotechnical and radio-electronic products must be designed and manufactured in such a way that they do not contain:

a) hazardous substances (Annex No. 2);

b) homogeneous materials that contain hazardous substances in a concentration that surpasses the acceptable level defined in the list included in the Annex 2 to the TR.

In other words, the scope of the substance restrictions under TR EAEU 037/2016 is similar to RoHS EU and concerns all homogeneous materials in electrotechnical and radio-electronic products and not the electrotechnical and radio-electronic products as a whole. Technically, point b) can be assumed as exemption from the general prohibition for the restricted substances in electrotechnical and radio-electronic products according to point a).

According to Annex 2 TR EAEU 037/2016 the restricted hazardous substances and the maximal admissible concentration levels in homogeneous materials by mass percentages (in brackets) are as follows:

- lead $(0,1 \%)$,

- mercury $(0,1 \%)$,

- cadmium (0,01\%),

- hexavalent chromium (0,1\%)

- polybrominated biphenyls (PBB) (0,1\%), and

- polybrominated diphenyl ethers (PBDE) (o,1\%).

Annex 3 TR EAEU 037/2016 also contains special exemptions regarding the usage of hazardous sub- stances in the electrotechnical and radio-electronic products. According to Section 12 Annex 3 TR EAEU 037/2016, there is, for example, no threshold for the concentration of lead in television tube glass. The same applies to mercury in metal-halide lamps, whereas the lead concentration in aluminum alloys may not exceed $0,4 \%$.

As a result of the comparison, it can be concluded that both in the EAEU and in the EU there are the same restrictions for six 'basic' substances, whereas the newly introduced restrictions for DEHP, BBP, DBP and DIBP in the EU are not (yet) appliable in the EAEU. Currently, there is no evidence indicating the intention to extend the substance restriction list in TR EAEU 037/2016 by inclusion of further substances, although the further inclusion of new substances would be generally possible. In this regard it has to be noted that the Eurasian Economic Commission in its Resolution No. 30 of 26. February 2020 adopted the draft of a Resolution ${ }^{14}$ which prescribes to amend the TR EAEU 037/2016 by extending the scope of its application, to update the requirements about hazardous substances and their concentrations in the electrotechnical and radio-electronic products and to include requirements about the disposal of electronic and radio-electronic products that lost their useful properties. The latter would be comparable to the requirements laid down in WEEE EU. According to the rules for lawmaking in the EAEU, the Republic of Belarus is responsible for elaborating a comprehensive draft of these new amendments until the fourth quarter of 2022 .

\section{Conformity Documentation and Certification}

One of the main differences between RoHS EU and TR EAEU 037/2016 are the requirements regarding conformity documentation and certification. Although both legislative regimes require the manufacturer of an EEE to perform a conformity assessment for the product regarding compliance with the aforementioned substance restrictions, the assessment procedure as well as the documentation and certification of conformity is completely different.

13 For further details cf. Article 5 RoHS EU.

14 Available at: <https://www.alta.ru/tamdoc/20r00030/> 


\section{RoHS EU}

According to Article 7(b) RoHS EU, the manufacturer has to draw up the required technical documentation and carry out the internal production control procedure in line with Module A of Annex II to Decision No $768 / 2008 / \mathrm{EC}^{15}$. As it is apparent from the wording 'internal production control', there is no obligation for the manufacturer to involve governmental or other official external authorities or institutions for drawing up the technical documentation. According to Module A of Annex II to Decision No 786/2008/EC the technical 'documentation shall make it possible to assess the product's conformity to the relevant requirements, and shall include an adequate analysis and assessment of the risk(s). The technical documentation shall specify the applicable requirements and cover, as far as relevant for the assessment, the design, manufacture and operation of the product. The technical documentation shall, wherever applicable, contain at least the following elements:

- a general description of the product,

- conceptual design and manufacturing drawings and schemes of components, sub-assemblies, circuits, etc.

- descriptions and explanations necessary for the understanding of those drawings and schemes and the operation of the product,

- a list of the harmonised standards and/or other relevant technical specifications the references of which have been published in the Official Journal of the European Union, applied in full or in part, and descriptions of the solutions adopted to meet the essential requirements of the legislative instrument where those harmonised standards have not been applied. In the event of partly applied harmonised standards, the technical documentation shall specify the parts which have been applied,

- results of design calculations made, examinations carried out, etc., and

- test reports.'

With regard to the drawing up of the technical documentation, DIN EN 50581:2013-02 'Technical docu-

15 Available at: <https://eur-lex.europa.eu/legal-content/EN/TXT/ PDF/?uri=CELEX:32008D0768\&from $=$ de $>$ mentation for the assessment of electrical and electronic products with respect to the restriction of hazardous substances' has to be taken into account. The core elements of this standard is that on the one hand information available to the manufacturer of an EEE should be assessed with regard to its quality, but on the other hand the trustworthiness of the person who provided the information should be taken into account as well. As far as the manufacturer applies the principles of DIN EN 50581 he can rely on the socalled presumption of conformity for its EEE. It has to be noted that in May 2019 DIN EN IEC 63000:2019-05 'Technical documentation for the assessment of electrical and electronic products with respect to the restriction of hazardous substances' was published but no reference on this standard has yet been included in the Official Journal of the European Union and thus the application of this standard does not yet lead to the presumption of conformity. Therefore, DIN EN 50581 is still of significance, until reference of DIN EN IEC 63000 will be published in the Official Journal of the European Union.

In case of compliance with the applicable requirements, the manufacturer has to draw up an EU declaration of conformity according to Article 7(c) in conjunction with Article 13 RoHS EU in the form and with the content specified in Annex VI RoHS EU. The declaration of conformity shall be available in the language or languages required by the Member State of the market on which the product is placed or made available, which leads to the necessity of several different language version in case a certain EEE is marketed throughout the whole EU. However, a registration of the declaration of conformity with a governmental or administrative authority is not necessary, but both, the technical documentation and the EU declaration of conformity has to be kept by the manufacturer for ten years after the last EEE of a series has been placed on the market according to Article 7 (d) RoHS EU.

\section{TR EAEU 037/2016}

The circulation of electrotechnical and radio-electronic products in the EAEU is requires a document confirming the compatibility of the products with TR EAEU 037/2016. The conformity of the electrotechnical and radio-electronic products is evaluated and confirmed by the issuance of either a confor- 
mity declaration (d (in Russian - д)) or a conformity certificate (c (in Russian - c). Applicants for conformity confirmation may choose the procedure to be applied by themselves. However, different procedures are reserved for each confirmation modes, and the procedures depend on factors such as the applying person, the subject of declaration (product type: batch of products or products of batch production), the existence of a certificate for the applicant's management system, the testing laboratory and several other factors.

In order to understand which confirmation procedure suits best, it should be determined what exactly (product of what type) must be certified/declared. TR EAEU 037/2016 distinguishes between the following types of products:

- Batch of Products (in Russian - 'партия продукции') - this means a set of products of one name and designation (if applicable) as specified in the shipping document the applicant provided for conformity evaluation. ${ }^{16}$ On a batch of products, the conformity confirmation procedures 2д and 4д; зс are applicable and may be applied for and performed by the manufacturer, the authorised representatives of the manufacturer or the importer/seller.

- Products of Batch Production (in Russian 'продукция серийного производства') products manufactured according to the same technical documents with the implementation of the same technological processes that is being released into circulation in the EAEU as a consecutive series of products or as recursive product batches. ${ }^{17}$ On products of batch production, the conformity confirmation procedures 1д, ЗД аnd 6 д; $1 \mathrm{c}, 2 \mathrm{C}$ and $6 \mathrm{c}$ are applicable. It has to be noted that only the manufacturer or the authorised representatives appointed by the manufacturer may apply for conformity confirmation for products of batch production.

The modalities of conformity verification depend on the way chosen for the confirmation of conformity as well and has to be made by using the proofs obtained by the applicant itself or through tests conducted by the certifying body. It is important to point out the following rule: Generally, conformity verification has to be conducted only by centers and laboratories included in the Unified Registry of the Customs Union ${ }^{18}$.
Confirmation of product conformity may take place in the following distinct types: ${ }^{19}$

a. Declaration (д) of the Conformity of Electrotechnical and Radio-Electronic Products

In the case of declaration, following documents have to be prepared:

- specification (if applicable);

- operation manual;

- testing protocol(s) for samples and/or parts, materials, components concerning their compatibility with this technical regulation and/or other documents volunteered by the applicant that justify the confirmation of compatibility of the products with this technical regulation (if applicable) (procedures 1Д, 2Д, ЗД, 4Д and 6Д); - special document for conformity confirmation in the form of testing

- supply agreement (contract) and shipping documents (if applicable) (for batches of products, single products) (procedures 2д and 4д);

- (copy of) certificate for the quality management system.

Electrotechnical and radio-electronic products can be declared using (depending on the declaration procedure) proofs the manufacturer/importer generated or collected itself and/or the proofs obtained with the help of an accredited testing laboratory (center) included in the Unified Registry of Certifying Bodies and Testing Laboratories (centers) of the Customs Union (Unified Registry) or from another laboratory (applicable only for procedures зд, 4Д и 6д).

The conformity declaration must be registered in the Unified Registry of issued Conformity Certifi-

16 Section 10, Paragraph II of Resolution of the Council of the Eurasian Economic Commission No. 44 About typical conformity evaluation procedures of 18 April 2018, available at: <http://www .consultant.ru/document/cons_doc_LAW_300366/ 92d3e3d03094ed76da5c15fa72b687f1 cebd5931/>

17 Section 10, Paragraph II of Resolution of the Council of the Eurasian Economic Commission no. 44 About typical conformity evaluation procedures of 18 April 2018

18 Detailed information about the Unified Registry of the Customs Union are laid down in the Resolution of the Eurasian Economic Commission No. 100 of 5 December 2018, available at: <http:// www.consultant.ru/document/cons_doc_LAW_318647/ 92d3e3d03094ed76da5c15fa72b687f1 cebd5931/>

19 Detailed information about declaration procedures are laid down in the TR EAEU 037/2016 and in the Resolution of the Council of the Eurasian Economic Commission No. 44 About typical conformity evaluation procedures of 18 April 2018. 
cates and registered Conformity Declarations. In order to register a conformity declaration, the applicant must submit the conformity declaration and a set of documents to the authorized (certifying) body.

Conformity declarations for electrotechnical and radio-electronic products produced in batches remain valid for no longer than 5 years. For conformity declarations for batches of electrotechnical and radio-electronic products no validity term has been defined.

\section{b. Certification of Electrotechnical and Radio- Electronic Products}

In the course of certification, the applicant submits the same documents to the certifying body which are required for declaration excluding the sample testing protocol(s). In order to conduct test and measurements, the body certifying the products hires, if necessary according to the applicable certification procedure, a cooperating, accredited testing laboratory to conduct the necessary tests and measurements.

Moreover, the registration of data about the conformity certificate with the unified registry of issued conformity certificates and registered conformity declarations is also done by the certifying body and not by the applicant itself.

Conformity certificates for electrotechnical and radio-electronic products produced in batches remain valid for no longer than 5 years. For conformity certificates for batches of electrotechnical and radioelectronic products no validity term has been defined.

It should be noted that the EAEU actively strives to create an information space and common databases to optimize the transfer of goods. To that effect a Unified Registry of Certifying Bodies and Testing Laboratories (centers) ${ }^{20}$ authorized to conduct tests for the confirmation of product conformity to TRs was established. At the moment there is a national part of registry ${ }^{21}$ (it contains list of laboratories (centers) on the territory of EAEU Members States) and

20 The information regarding Unified Register of Certifying Bodies and Testing Laboratories (centers) available at <http://www .eurasiancommission.org/en/docs/Pages/IL_OS.aspx>

21 For Russian Federation available at <https://en.fsa.gov.ru/about/>

22 Information regarding the Unified Registry of issued Conformity Certificates and registered Conformity Declarations available at $<$ https://portal.eaeunion.org/sites/commonprocesses/ru-ru/Pages/ ConformityDocsRegistryDetails.aspx> a Unified Registry on EAEU level, which encompasses Certifying Bodies and Testing Laboratories (centers) from all Member States of the EAEU. These databases also exchange data between national and EAEU parts of the Register. Besides this, the Unified Registry of issued Conformity Certificates and registered Conformity Declarations was established. ${ }^{22}$ It is based on the same idea as the Unified registry of Certifying Bodies and Testing Laboratories (centers) and integrates information regarding certificates and declarations from all Member States of the EAEU. The functionality of the Unified Registries and of the data exchange between different levels of the Registries is not perfect at the moment and thus demands further development and technological process refinement. However, the existence of such unified databases on the Internet allows to quickly verify whether the document that confirms the compatibility of the merchandise with the TR EAEU 037/2016 really exists as well as its veracity.

\section{Labelling Requirements}

Another important aspect to be considered when placing an EEE on the market, is its labelling. Although it might be assumed that the violation of a labelling requirement can be considered a formal, minor incompliance, it should be borne in mind that the violation of a labelling requirement is the easiest to detect and might lead to further investigations. Thus, a compliant labelling of an EEE should be considered at least as important as compliance with other requirements.

\section{RoHS EU}

According to Article 7(g) and (h) RoHS EU an EEE has to be labelled by its manufacturer with a type, batch or serial number or other element allowing its identification, with the name, registered trade name or registered trade mark of the manufacturer and with the address at which the manufacturer can be contacted on the EEE. The address must indicate a single point at which the manufacturer can be contacted. As a rule, these labelling elements have to be shown directly on the EEE as such, whereas the mere labelling of the packaging and/or accompanying documents is not sufficient. In the exemptional case 
however, it is not possible to directly show the labelling elements on the EEE due to its size and/or nature, it is admissible to provide the necessary information on the packaging or in a document accompanying the EEE.

Furthermore, the manufacturer has to affix the $\mathrm{CE}$ mark $^{23}$ to the finished product according to Article 7(a) in conjunction with Article 14 and 15 RoHS EU in conjunction with Article 30 of Regulation (EC) No $765 / 2008^{24}$. Again, as a rule, the CE marking shall be affixed visibly, legibly and indelibly directly to the finished EEE and only in exceptional cases, where that is not possible or not warranted on account of the nature of the EEE, the CE marking shall be affixed to the packaging and to the accompanying documents. By affixing the CE marking, the manufacturer indicates that he takes responsibility for the conformity of the product with all applicable requirements, in particular with the substance restrictions, set out in RoHS EU.

In addition to these labelling requirements, WEEE EU lays down further labelling obligations. Article 14(4) WEEE EU obliges to provide for a visible, legible and indelible labelling directly on the EEE with the symbol of a crossed-out wheeled bin. The labelling should take place in accordance with DIN EN 50419. It has to be noted that, contrary to the labelling elements according to RoHS EU, when in exceptional cases the crossed-out wheeled bin cannot be affixed directly on the EEE because of the size or function of the EEE, the symbol shall be printed on the packaging, on the instructions for use and on the warranty of the EEE without a choice for the manufacturer. The crossed-out wheeled bin shall inform the end-users of EEE that it may not be disposed as unsorted municipal waste but has to be gathered and disposed separately in order to allow the resources contained in the waste EEE to be recovered and recycled.

\section{TR EAEU 037/2016}

The labeling requirements under TR EAEU 037/2016 are laid down in Paragraphs V. and VIII. of TR EAEU 037/2016. The Regulation contains requirements about the labeling of products and about the packaging, as well es requirements for the operational document. The following elements have to be printed on the product surface:
- name and/or designation of the electrotechnical or radio-electronic products (type, brand, model (if applicable)) - must also be printed on the packaging;

- main parameters and characteristics,

- manufacturer's name and/or trademark - must also be printed on the packaging;

- name of the country in which the electrotechnical or radio-electronic product was produced.

These elements must also be included in the operation manual, which has to be made out in print for electrotechnical or radio-electronic product for domestic use. The labels and operation manuals must be written in Russian in any case and additionally in the Member State language(s) where the product is being sold, if the respective national law requires so.

Electrotechnical and radio-electronic products that successfully accomplished the procedure of conformity verification must carry a unified product circulation mark of the EAEU. The mark was approved by the Resolution of the Commission of Customs Union No. 711 About the unified product circulation mark of the EAEU market and the relevant usage procedure of 15.07.2011 (version of 17.03.2016) ${ }^{25}$ together with the Procedure for usage of the unified product circulation mark of the EAEU market. The mark consists of the three letters 'EAC', which mean Eurasian Conformity. The unified product circulation mark of the Union shall be affixed before the electrotechnical or radio-technical products is released for circulation on the Union market.

The unified product circulation mark of the Union must be affixed on every electrotechnical or radiotechnical products in such a way that it is ensured that the mark is clearly visible throughout the whole service life of the product. In case it is impossible to affix the EAC mark to the electrotechnical or radiotechnical product, it has to be affixed on the product packaging instead. In any case, the EAC-mark must also be included in the operation manuals enclosed with the product. Both depicted versions of the EAC mark, with either black letters on white ground or

23 CE marking files available at: <https://ec.europa.eu/growth/single -market/ce-marking_en>

24 Available at: <https://eur-lex.europa.eu/legal-content/EN/ALL/?uri $=$ celex:32008R0765>

25 Available at: <http://www.consultant.ru/document/cons_doc _LAW_117846/> 
white letters on black ground, have the same meaning, however the manufacturer is obliged to choose the variation which contrasts best to the background.

\section{Obligations of an Importer}

Apart from the manufacturer, the importer of an EEE into the European Union or into the Eurasian Union has certain obligation, which in many aspects depend on the fulfilment of the obligations of the manufacturer.

\section{RoHS EU}

The general obligations to be fulfilled by an entity qualifying as importer are laid down in Article 9 RoHS EU.

In a nutshell, the importer has to ensure that he only places devices on the market which comply with RoHS EU. This encompasses to ensure that the appropriate conformity assessment procedure has been carried out by the manufacturer, that the manufacturer has drawn up the technical documentation, that the EEE bears the CE marking, is accompanied by the required documents and that the manufacturer has complied with its labelling obligations.

Beside the labelling of the manufacturer, which remain unaffected, the importer is as well obliged to indicate its name, registered trade name or registered trademark and the address at which it can be contacted on the EEE according to Article 9(c) RoHS EU. Again, where it is not possible to affix these labelling elements directly on the EEE, they have to be provided on its packaging or in a document accompanying the EEE.

It has to be noted that according to Article 11 RoHS EU an importer is considered a manufacturer for the purposes of this Directive and that he is subject to the obligations of the manufacturer under Sec. 4 , 5 and 11 ElektroStoffV, where it either places the device on the market under his name or trademark or modifies EEE already placed on the market in such a way that compliance with the applicable requirements may be affected. However, based on the struc-

26 Equal to EUR 644.00 to EUR 3862.00 (calculated on 9 June 2020 - RUB 1.0 = EUR 0.013) ture of RoHS EU, this covers only the constellation in which only the importer is indicated on the device without any reference to the actual manufacturer.

\section{TR EAEU 037/2016}

The mandatory rules described above apply to all electrotechnical and radio-electronic products coved by the TR EAEU 037/2016, imported into as well as manufactured in a Member State of the EAEU, for example Russia, independently of the intended sale location. The confirmatory document will thus be verified by the customs authorities when the products are imported in the EAEU.

Conformity certificates are required for customs clearance when the products are being imported into the EAEU. The liability of legal entities for violations of product export or import requirements is defined on national level. In Russia , it is defined in Article 16.3 of the Administrative Offences Code of the Russian Federation as violation of bans and/or restrictions on import of products in the customs area of the Eurasian Economic Union or in the Russian Federation and/or export of products from the customs area of the Eurasian Economic Union or from the Russian Federation. A violation can be sanctioned with an administrative fine starting from RUB $50,000.00$ up to RUB $300,000.00^{26}$ for legal entities with the possibility of additional confiscation of goods which violated the administrative rules. In the light of, from a European perspective, relatively moderate fines, the confiscation of the goods in case of a violation of the requirements of TR EAEU 037/2016 is substantially more burdensome und in most cases will lead to much higher costs compared to the imposed fines.

\section{Conclusion}

The restriction of the use of hazardous substances in the EAEU and the EU is in general quite similar. So, for example, both pieces of legislation determine certain substance restrictions, contain certain exemptions and demand for compliance documentation and labelling.

However, despite of the similarities, the procedure of compliance documentation in Russia or better to say in the EAEU extremely differs from the proce- 
dure in the EU. In the EAEU there are different schemes of conformity confirmation depending on the type of product, the applicant, the testing procedure, the certifying body and some other points. Whereas the declaration of conformity, issued by the manufacturer itself, is together with the technical documentation the sole compliance document in the $\mathrm{EU}$, there are two main options for an applicant to demonstrate compliance with TR EAEU 037/2016 certification or declaration - which both demand for the registration of the certificate or declaration with an administrative body.

In a nutshell, the comparison of the applicable (technical) regulations in the field of electrotechnical and radio-electronic products in EAEU and EU shows that the importance of the limitation of hazardous substances in electrotechnical and radio-electronic products (or EEE) is recognized on an international level, which led to the adoption of special rules. However, until now, there is no international unified procedure of conformity assessment and documentation, which leads to the burden that internationally acting companies have to double-check the compliance of their products as well as their corresponding documentation and labelling with the numerous, mandatory applicable regulations throughout the world. This results in additional expenses of time and money. Therefore, the best option would be to agree on a common unified system of substance restrictions and corresponding compliance documentation and labelling in order to avoid the imposture of additional hurdles for trade by imposing different requirements on globally actin companies. Since this seems to be a faraway fantasy at the very point in time, globally acting companies have to cope with these differences and find ways to adapt to it. 